\title{
ENSINO MÉDIO E PROCESSOS FORMATIVOS NA CONSTRUÇÃO DE SABERES SOCIAIS EM UM CONTEXTO AMAZÔNICO ${ }^{1}$
}

\author{
Kariny de Cássia Ramos da Silva ${ }^{2}$ \\ Doriedson do Socorro Rodrigues ${ }^{3}$ \\ João Batista do Carmo Silva ${ }^{4}$
}

\begin{abstract}
RESUMO
Neste artigo, expomos resultados de pesquisa sobre os processos formativos oriundos das relações produzidas e vivenciadas por jovens trabalhadores, inseridos no Ensino Médio do Sistema de Organização Modular de Ensino (SOME), da Secretaria de Estado de Educação (SEDUC-PA), entre os anos de 1997 a 2007, como consequências de um processo dialético de resistência e produção de habilidades, conhecimentos, valores, atitudes e saberes originários das contradições decorrentes das lutas travadas por esses jovens trabalhadores contra a lógica capitalista de degradação e fragmentação dos processos formativos presentes no SOME, na Vila de Juaba, município de Cametá, Pará-Brasil. Metodologicamente, trata-se de pesquisa de cunho qualitativo, recorrendo-se à pesquisa bibliográfica, documental e de campo, bem como entrevista semiestruturada e questionário no bojo da Análise de Conteúdo, chegando-se à conclusão de que a formação dessas juventudes se pautou em uma relação contraditória de afirmação e negação de seus saberes sociais, diante das contradições de uma conjuntura permeada pelas ações do capital na região, sendo observadas formas de produção de saberes paralelos ao ensino formal, sob influência do capital, modificando os modos tradicionais de desenvolvimento sócio-cultural, organizacional e político dos jovens.
\end{abstract}

Palavras-chave: Ensino Médio. Processos formativos. Saberes sociais. Juventudes.

\begin{abstract}
In this article, we present research results on the formative processes resulting from the relations produced and experienced by young workers, inserted in the High School of the Modular Teaching Organization System (SOME), of the State Secretariat of Education (SEDUC-PA), among from 1997 to 2007, as a consequence of a dialectical process of resistance and production of skills, knowledge, values, attitudes and knowledge originating from the contradictions arising from the struggles of these young workers against the capitalist logic of degradation and fragmentation of the present formation processes in SOME, in the town of Juaba, municipality of Cametá, Pará-Brazil. Methodologically, this is a qualitative research, resorting to bibliographical, documentary and field research, as well as a semi-structured interview and questionnaire in the content analysis field, reaching the conclusion that the formation of these youths was based on a contradictory relation of affirmation and negation of

\footnotetext{
${ }^{1}$ O presente artigo resulta de dissertação defendida, em 2018, no Programa de Pós-Graduação em Currículo e Gestão da Escola Básica (PPEB), Universidade Federal do Pará, sob o título "Integração e fragmentação dos processos formativos na conjuntura de implantação do sistema modular de ensino médio em um contexto amazônico".

${ }^{2}$ Mestra em Currículo e Gestão da Escola Básica (UFPA). Técnica da Secretaria Municipal de Educação de Cametá. Membra do Grupo de Estudos e Pesquisas sobre Trabalho e Educação (GEPTE/UFPA). E-mail: ramoskariny@yahoo.com.br

${ }^{3}$ Docente da Faculdade de Linguagem e Coordenador do Campus Universitário do Tocantins/Cametá, Universidade Federal do Pará (UFPA). Docente do Programa de Pós-Graduação em Educação e Cultura (PPGEDUC/UFPA) e do Programa de Pós-Graduação em Currículo e Gestão da Escola Básica (PPEB/UFPA). Membro do Grupo de Estudos e Pesquisas sobre Trabalho e Educação (GEPTE/UFPA). E-mail: doriedson@ufpa.br

${ }^{4}$ Docente da Faculdade de Educação, Campus Universitário do Tocantins - Cametá, Universidade Federal do Pará (UFPA), Cidade de Cametá, Pará, Brasil. Membro do Grupo de Estudos e Pesquisas sobre Trabalho e Educação (GEPTE/UFPA). E- mail: jbatista@ufpa.br
} 
their social knowledge, in the face of the contradictions of a conjuncture permeated by the actions of capital in the region, being observed forms of production of knowledge parallel to formal education under the influence of capital, modifying the traditional modes of development partner -cultural, organizational and political life of young people.

Keywords: High School. Formative processes. Social knowledge. Youth.

\section{INTRODUÇÃO}

No presente texto apresentamos alguns dos resultados de pesquisa acerca de processos formativos $^{5}$ de juventudes no Ensino Médio do Sistema de Organização Modular de Ensino$\mathrm{SOME}^{6}$, da Secretaria de Estado de Educação (SEDUC-PA), entre os anos de 1997 e 2007, objetivando responder às seguintes questões: como ocorreram os processos de construção de saberes sociais no Ensino Médio, por meio dos processos formativos realizados no SOME?; como foram desenvolvidos os processos de integração e fragmentação de saberes no Ensino Médio no contexto da Vila de Juaba, Cametá-PA?

Metodologicamente, é uma pesquisa de cunho qualitativo, que se pauta em revisões bibliográficas, pesquisa de campo, entrevista semiestruturada, segundo Minayo (2010), junto a quatro egressos do SOME e dois Professores que atuaram no período correspondente a 1997 e 2007. Ressaltamos que para a obtenção dos depoimentos orais, durante as entrevistas semiestruturadas que foram realizadas nas residências dos entrevistados, utilizou-se o gravador de voz para captar as falas dos entrevistados e, posteriormente, feita transcrição dessas falas, utilizou-se a técnica da Análise de Conteúdo para tratar os dados por compreendermos que o conteúdo e seus significados devem ser pautados na história e no contexto social dos sujeitos.

Em termos estruturais, este texto é constituído, além desta introdução, por sessões. $\mathrm{Na}$ primeira sessão, tratamos do "Ensino Médio e divisão técnica do trabalho: integração e fragmentação do ensino inscritas nas reformas educacionais brasileiras". $\mathrm{Na}$ segunda, abordamos "Produção de saberes e formação das juventudes trabalhadoras no SOME: a práxis política". Por fim, expomos as considerações finais.

\footnotetext{
${ }^{5}$ No SOME, no decorrer das análises, os processos formativos revelaram-se de duas formas: integradores e fragmentários dos saberes das juventudes. Contudo, compreende-se que, para consubstanciar uma formação integradora de saberes, há de se "[...] constituir uma educação unitária - o que não pode ser confundido com práticas uniformes e padronizadas[...]" (RUMMERT, 2011, p. 157).

${ }^{6}$ SOME vem se configurar como uma política pública, revelando-se como uma alternativa para jovens estudantes que não têm condições de sair de suas localidades. Além disso, tem uma forma peculiar em sua metodologia: as disciplinas são ministradas em módulos, diferentemente do que ocorre com o Ensino Médio Regular, e acontecem em uma conjuntura de educação do/no campo.
} 


\section{ENSINO MÉDIO E DIVISÃO TÉCNICA DO TRABALHO: INTEGRAÇÃO E FRAGMENTAÇÃO DO ENSINO INSCRITAS NAS REFORMAS EDUCACIONAIS BRASILEIRAS}

No decorrer da História da Educação no Brasil, a dualidade educacional, que fragmenta conteúdos, práticas, relações, saberes, limita a escola a reafirmar ou reproduzir "um habitus de classes", já que ela somente aplica benefícios "[...] àqueles que beneficiaram para lá do recinto escolar e bem antes de lá entrarem, no seio familiar dos hábitos de família, de um certo estilo de vida" (SNYDERS, 1976, p. 23).

Destarte, a cultura que a escola imprime aproxima-se da cultura das classes privilegiadas, assemelhando-se à classe social a que os discentes pertencem, por isso os que já trazem para a escola, por meio da educação familiar, a cultura produzida em suas relações sociais não terão tantas dificuldades de aprendizagem, já que não é algo diferente do habituado, ao contrário dos discentes que têm raro acesso à cultura socialmente privilegiada no seio de relações de classe, proveniente de relações sociais e familiares distantes de práticas culturais consideradas mais elitizadas (SNYDES, 1976).

Partimos do pressuposto de que a sociedade é constituída da ordenação em classes e a história da educação brasileira revela que a dualidade é evidenciada na produção social, na apropriação da terra, da riqueza e da distribuição dos saberes, este último podendo ser percebido, com maior clareza, no nível do Ensino Médio (FRIGOTTO; CIAVATTA; RAMOS, 2005).

O Ensino Médio, no dizer de Nosella (2016), é relevante para o processo de democratização do país revelando sua posição estratégica, uma vez que a proposta de educação estatal depende do projeto de sociedade a que ela se destina, existindo "[...] uma íntima relação político-cultural entre a escolarização média e a elevação social desse setor. A atenção dada a esse nível de ensino pelo Estado depende de sua concepção de hegemonia nacional e de sistema escolar (Idem, p. 71).

No período entre 1997 e 2007, o Brasil aprovou a Lei de Diretrizes e Base da Educação Nacional, Lei No 9.394/1996, apresentando resultados quanto à sua implementação, mas havendo profunda regressão em relação ao projeto de Ensino Médio Integrado, mediante a aprovação do Decreto $N^{o}$ 2.208/1997, ao restabelecer o dualismo no Ensino Médio, assumindo a orientação do ensino técnico com ideário pedagógico de mercado, tendo a Pedagogia das Competências para a empregabilidade como norteadora; ou seja, o Decreto 
regulamentou a educação profissional separada do Ensino Médio (FRIGOTTO, CIAVATTA, RAMOS, 2005).

Nesse período, em 1994, deu-se início no Município de Cametá à implantação de uma outra forma de oferta do Ensino Médio com a implementação do SOME: [...] como forma de atender a estas especificidades dos sujeitos que vivem no e do campo, a microrregião de Cametá adota a modalidade de ensino, em 1994 [...]" (SOLEDADE; SILVA, 2013, p. 339). O Sistema de Organização Modular de Ensino é uma política de educação que tem dentre suas finalidades ofertar Ensino Médio para atendimento de discentes em localidades de difícil acesso ou com dificuldades estruturais por conta da sua localização (PARÁ, 2014), sendo a única política de interiorização do Ensino Médio no Pará com ensino presencial em funcionamento em estabelecimentos de ensino da rede pública municipal e com auxílio de sedes comunitárias nas localidades rurais.

A luta pela manutenção de uma hegemonia ou pela construção de uma materialidade contra hegemônica, em termos gramscianos, evidencia a existência de duas classes sociais: a burguesia e o proletariado. O Ensino Médio, nesse contexto social, apresenta-se também dual: atende às elites dirigentes representadas pela oferta de ensino que lhes fomenta formação geral e outro que atende à classe trabalhadora com preparação para o trabalho imediato. No caso do SOME na Vila de Juaba, pode ser chamado de "ornitorrinco", segundo Oliveira (2013), ao se compreender que o mesmo trata a educação para a classe trabalhadora sem uma infraestrutura para seu funcionamento e nem condições de organização pedagógica e administrativa adequadas para o ensino, constituindo-se um Estado Mínimo quanto à oferta desse Ensino Médio.

De outro modo, o Ensino Médio Integrado se coloca como uma proposta de integração entre a formação geral e a educação profissional como superação do já tradicional dualismo da sociedade e na educação brasileira com efetiva presença do Estado nesse contexto. O que vem retomar essa discussão sobre esta modalidade de ensino é a revogação do Decreto 2.208/1997, em 2004, com a aprovação na Comissão da Câmara do Decreto 5.154/2004, que resgata a base unitária do Ensino Médio em uma tentativa de restabelecer o que se vinha construindo com a LDB de 1996.

Assim, o que se quer com o Decreto 5.154/2004 é o reconhecimento do Ensino Médio como um nível formativo em consonância com o trabalho, enquanto princípio educativo, promovendo a ciência como força produtiva com vistas à superação da divisão técnica do trabalho, associada à realidade brasileira, trazendo o compromisso ético e político da 
formação em possibilitar aos jovens desenvolvimento de sua capacidade de autonomia frente aos desafios impostos pelo mercado de trabalho e, finalmente, trabalhar no Ensino Médio a formação geral integrada à formação técnica (FRIGOTTO; CIAVATTA; RAMOS, 2005).

No mesmo período, no Estado do Pará, começou a ser trabalhado o projeto de Ensino Médio Integrado, segundo a proposta da SEDUC-PA, “[...] reafirmando a defesa da função social da Educação Básica em formar cidadãos com capacidades para trabalhar, para viver em comunidade, para a vida política e cultural e para a convivência familiar[...]" (PARÁ, 2009, p. 11).

A partir de 2007, a SEDUC-PA deu início ao processo de implementação da política de Educação Básica com base nas deliberações da Conferência que aprovou as diretrizes, metas e objetivos para a configuração do Plano Estadual de Educação, indicando o Ensino Médio Integrado como política pública para esse nível de ensino. O SOME se inscreve nessa nova agenda da Educação no Estado com o objetivo de “[...] oferecer uma Educação de qualidade, e, por conseguinte, garantir que todos os sujeitos que se encontram em contextos específicos possam ter acesso ao processo de escolarização [...]” (PARÁ, 2009, p. 18). C

Contudo, na prática, problemas estruturais, pedagógicos, contribuíram para que esse objetivo constituísse muitas vezes apenas o plano das ideias, quanto a esses elementos. A Educação do Campo, por exemplo, exige um olhar cuidadoso sobre a realidade desses sujeitos, pois essa realidade "[...] denuncia grandes desafios a serem enfrentados para que sejam cumpridos os marcos operacionais anunciados nas legislações educacionais que definem os parâmetros de qualidade de ensino público", fruto de conquistas de "lutas dos movimentos sociais populares do campo" (HAGE, 2005, p. 44).

Com o movimento de aprovação da LDB 1996, passando pela aprovação e revogação do Decreto 2.208/1997 e a aprovação do Decreto 5.154/2004, entende-se que a realidade social a que estes jovens estavam imersos sofreu outra configuração, ocasionando uma nova forma de olhar para o SOME.

A defesa do movimento social do "[...] direito dos trabalhadores à educação é uma proposta mais radical do que apenas defender escola para todos [...]" (ARROYO, 2011, p. 106), no que se concorda, assim como o Decreto 5.154/2004, veio confirmar essa perspectiva quando retoma a unificação do ensino técnico ao Ensino Médio, em uma proposta de trabalho como princípio educativo por ofertar ensino que integra as múltiplas dimensões da vida do jovem (MANACORDA, 2008). 
A garantia de universalização do Ensino Médio (BRASIL, 1996) possibilitou a chegada do SOME na microrregião de Cametá $^{7}$, mas não conseguiu garantir a oferta de ensino de com qualidade para a juventude da região, em termos de estrutura física e de processos de integração, mesmo que propostas, como a do Decreto 5.154/2004, ampliem e ressignifiquem a oferta da educação, também, para a juventude de Juaba, quando reconfigura e garante a integração entre os saberes provenientes da prática cotidiana dos jovens aos saberes científicos ofertados no SOME.

Compreende-se que o SOME é uma política pública de educação necessária para a formação da juventude em um contexto amazônico, representado, aqui, pela Vila de Juaba no Município de Cametá, mas que somente sua permanência na localidade não materializa uma formação inteira (ARAUJO, 2014). Considera-se, nesse contexto, no interior das lutas de classes, a hegemonia como construção política, objetivando o fortalecimento de classe para transformação da realidade, levando em conta, para tal, os interesses da classe trabalhadora e tendo o Ensino Médio Integrado como mecanismo para efetivar essa proposta.

\title{
2. PRODUÇÃO DE SABERES E FORMAÇÃO DAS JUVENTUDES TRABALHADORAS NO SOME: A PRÁXIS POLÍTICA
}

Para analisar processos formativos no contexto das relações humanas, faz-se necessário compreender que o ser humano é, antes de tudo, um processo que se articula nos diversos aspectos sociais, como socioeconômico, político e formativo. Esses elementos proporcionam ao ser humano a produção de saberes nas suas condições reais. O ser humano, antes de qualquer relação com outros tipos de conhecimentos, já acumulou saberes oriundos de suas relações cotidianas, possui concepções de mundo e de sociedade.

Essas concepções de mundo são manifestadas na fala do egresso Lopes ${ }^{8}$ conforme o conteúdo trabalhado nos processos formativos no SOME.

\begin{abstract}
A aproximação, no caso, com os conteúdos da região, por exemplo, nós tivemos trabalho para pesquisa para montar maquete pra falar como era a vida dos ribeirinhos, do povo da colônia, quando a gente fala o povo ribeirinho, o povo da colônia é porque parece que aqui é diferente, e aí nós tivemos trabalhos para a produção da farinha, o manejo do açaí, a questão da pesca, então tinha essa aproximação com a nossa realidade, agora a gente sabe que o Ensino Médio ele tem uma estrutura de conteúdo, que eles não poderiam deixar de lado, aí na medida do possível eles faziam essa relação.
\end{abstract}

\footnotetext{
${ }^{7}$ Essa Microrregião é compreendida pelos municípios de Cametá, Mocajuba, Oeiras do Pará, Limoeiro do Ajuru e Baião.

${ }^{8}$ Nome fictício adotado para preservar a face pública do entrevistado.
} 
Trata-se de processos formativos que consideram saberes resultantes de uma "produção real", que é construída partindo da vivência dos discentes em sua comunidade e em relação com outros moradores por meio de ações promovidas pelos docentes do SOME “[...] em uma atividade concreta socialmente útil [...]" a fim de consubstanciar a base "[...] indispensável para analisar e estudar todos os fenômenos sociais" (PISTRAK, 2011, p. 30).

Assume-se, então, a perspectiva de que “[...] é preciso, portanto, 00desenvolver no professor, a todo custo, a aptidão para a criatividade pedagógica; senão, será impossível criar a nova escola" (PISTRAK, 2011, p. 21).

Significou dizer que "[...] a qualidade das aprendizagens dos alunos depende da qualidade do desempenho profissional dos professores. Essa qualidade, no geral, tem sido extremamente precarizada [...]" (TARDIF, 2002, p. 13). Nas palavras do interlocutor da pesquisa, o Professor Carlos, “[...] até porque eu penso, que é um compromisso nosso, não é porque existe um obstáculo que vou ter que vir... eu sei que é de responsabilidade da URE, mas às vezes não está ao alcance dos gestores solucionar todo tipo de problema".

O enunciado do Professor Carlos sobre a forma de pensar a sua prática remete à ideia de responsabilidade total a respeito da prática dos Professores, de modo que tal afirmação alcança o campo apenas da pseudoconcreticidade da aparência (KOSIK, 1976), a julgar que a estruturação física do SOME, bem como de todo o ensino público no Brasil, é de inteira responsabilidade Estatal (BRASIL, 1996).

A supervalorização das práticas imediatas na fala do Professor Carlos é que o docente precisa efetivar em determinados momentos da vida cotidiana escolar, evidenciando como aconteciam as aulas no período entre 1997 e 2007, na localidade de Vila de Juaba, mas, neste caso, trata-se de uma questão social e não pedagógica. O problema parte da sociedade e não da Escola.

Ocupa-se, neste sentido, de se aferir sobre as práticas desenvolvidas no SOME em oposição aos limites impostos a estas práticas, de modo a permitir que os Professores continuem a desenvolver práticas formativas integradoras, mas com condições de trabalharem ética e politicamente a integração dos saberes do cotidiano dos discentes aos conhecimentos científicos, consubstanciando "[...] a entrada do aluno na vida, depois da escola, deixa de ser um salto no desconhecido, tonando-se uma transição bastante fácil e, quanto mais passar despercebida, melhor será para o aluno" (PISTRAK, 2011, p. 73).

A materialização desse ensino com um conteúdo político-pedagógico de que fala Pistrak (2011), Araujo (2014), entre outros, com práticas formativas integradoras, efetiva um 
Ensino Médio em que os professores comprometidos com o ensino desenvolvem por meio de suas ações, "[...] até porque a educação ainda é um viés para que se consiga ter um ganho, um rendimento... esse envolvimento ele parte mais do Professor do que da própria comunidade", segundo professor Carlos.

Para o Professor $\operatorname{Carlos}^{9}$ a prática docente pode ser apreendida, pois,

normalmente, a gente procurava, dentro das nossas disciplinas, buscar um trabalho realizado pelos próprios alunos, que poderia ser envolvendo a dança, a música, o teatro, o artesanato e nós fazíamos em forma de exposição, nos reuníamos... os alunos expunham os trabalhos, quem fez artesanato fazia tipo uma feirinha, quem quisesse adquirir e é muito bonito porque estimula a cultura, a gente promove a cultura e faz com que eles se sintam também partes atuantes desse processo do ensino-aprendizagem, não só um receptor de informações, mas quando eles agem como sujeitos desse processo, eles se sentem mais próprios e é mais incentivo para que eles continuem a buscar o melhor pra eles, é o que chamamos de culminância de final de módulo, inclusive nós atribuímos uma nota pela participação, pelo envolvimento deles.

Os estudantes compreendem, dessa forma, que, no interior das relações sociais desenvolvidas na Vila de Juaba, mais especificamente no SOME, a relação entre a sua cultura, o seu artesanato, a música local, o teatro como metodologia para trabalhar as disciplinas do curso, lhes permitem desencadear ações de enfrentamento da realidade de negação de condições mínimas de ensino por eles vivenciado. Tudo isso pela articulação dos seus saberes aos saberes ministrados pelos Professores. Dessa forma, observa-se a integração nos aspectos socioeconômico, político e formativo.

O egresso do SOME, em termos formativos, possui um saber que advém de sua prática cotidiana em produzir a farinha, em manejar o açaí, sobre a pesca, que são saberes socialmente construídos e operacionalizados em acordo com as necessidades que a vida cotidiana e sua experiência lhe requerem. Em termos de formação no âmbito do SOME, esses saberes socialmente construídos vão sendo relacionados aos poucos saberes científicos por meio dos processos formativos, como menciona o Professor Carlos, "na medida do possível", o que constitui uma integração, mesmo que principiante, do conteúdo.

As falas dos entrevistados permitem inferir que coexistem forças antagônicas no processo de construção ou ressignificação dos saberes dos jovens egressos do SOME, em movimento dialético, que se desenvolve integrando os saberes no "[...] trabalho de montar maquete para falar como era a vida do povo ribeirinho, do povo da colônia [...]” e, de outro modo, fragmenta sua experiência ao limitar a prática dos Professores, uma vez que essa

\footnotetext{
${ }^{9}$ Formado em Letras e Docente do Estado atuando há 37 anos. Nome fictício adotado para preservar a face pública do entrevistado.
} 
constituição dos saberes sociais acontecia "na medida do possível”, por não ofertar condições estruturais, comprometendo o modo como essa formação acontecia; contudo, emerge desse processo um saber que resulta em saber orgânico, um saber que mobiliza os egressos por melhorias em sua qualidade de ensino.

Esses saberes, resultantes das necessidades em produzir sua sobrevivência, foram ressignificados com a chegada do SOME na região, pois este oportunizou aos egressos a possibilidade de ampliação de seus saberes sobre a produção da farinha, por exemplo, necessários à subsistência da comunidade de Vila de Juaba. Nessa sequência, investigado sobre a prática dos Professores do SOME em relacionar os conteúdos curriculares aos saberes dos alunos, conforme expressa o egresso Alonso ${ }^{10}$ :

Principalmente da roça. Isso que me despertou também, eles trabalhavam muito, por
exemplo: a maniva ${ }^{11}$. Como é que vocês fazem para plantar a maniva? Aí o
professor perguntava: como vocês fazem lá? Ah, lá a gente, todo mundo trabalha
tudo junto. Eles trabalhavam muito em cima da muda. Como é que se faz a muda de
uma planta? Aí eles (os professores) disseram: mas não vai machucar a maniva?
Vai, porque ela tem os olhinhos que grelam, aí se a gente cortar um pedaço grande,
que têm seis olhinhos, três não vão prestar, porque machuca na hora que corta ele
quebra dois, três. Aí ele falou: mas tem que fazer o seguinte: tem que pegar o
terçado e cortar ele aqui assim com cuidado para não machucar e assim vai ter um
aproveitamento melhor, sem desperdiçar.

Os jovens estudantes, objetivando alcançar suas necessidades, deflagram-se com sua realidade e nesse flagrante eles vão pensando, materializando e construindo sua atividade prática enquanto satisfação de suas necessidades consubstanciando formas outras de se relacionar com a realidade, por fim, gerando saberes, valores, conhecimentos, em meio a novas realidades, tanto conceituais como materiais, já que essa realidade é resultante da integração teoria-prática, mas sem esquecer que "[...] entre a teoria e a atividade prática transformadora se insere um trabalho de educação das consciências, de organização dos meios materiais e planos concretos de ação; tudo isso como passo indispensável para desenvolver ações reais efetivas [...]" (VÁZQUEZ, 2011, p. 237).

Essa articulação entre teoria e prática somente pode ser efetivamente aplicada no contexto educacional se as condições materiais forem ofertadas, no dizer de Gramsci (1982), “[...] também a questão dos prédios não é simples, pois este tipo de escola deveria se ter uma escola-colégio, com dormitórios, refeitórios, bibliotecas especializadas, salas aptas ao trabalho de seminário etc.”. Para o autor, “[...] o novo tipo de escola deverá ser e não poderá deixar de

\footnotetext{
${ }^{10}$ Nome fictício adotado para preservar a face pública do entrevistado.

${ }^{11}$ Maniva: tolete ou folha da planta da mandioca; usa-se na alimentação na região Norte, especialmente no Pará.
} 
ser própria de grupos restritos, de jovens escolhidos por concurso ou indicados, sob sua responsabilidade, por instituições idôneas" (GRAMSCI, 1982, p. 121).

Partindo de saberes organizacionais por meio de processos formativos integradores, infere-se que a organização e a organicidade dos Professores do SOME, ao integrar e fragmentar os processos formativos em um movimento dialético, conduzem a uma formação que ora avança e ora retroage no sentido de uma formação integral.

Esses saberes sociais, que também foram integrados pelos processos formativos, como o voltado para a organização buscando o Ensino Médio, envolveu a comunidade na objetivação de sanar suas necessidades por maior conhecimento científico dos seus alunos, e teve, como perspectiva, a formação dos jovens enquanto "intelectual orgânico" (GRAMSCI, 1982, p. 8).

Esse tipo de formação requer uma elaboração:

criticamente da atividade intelectual que existe em cada um em determinado grau de desenvolvimento, modificando sua relação com o esforço muscular-nervoso no sentido de um novo equilíbrio e conseguindo-se que o próprio esforço muscular nervoso, enquanto elemento de uma atividade prática geral, que inova continuamente o mundo físico e social, torne-se o fundamento de uma nova e integral concepção do mundo(GRAMSCI, 1982, p. 8).

O Professor Carlos, em sua maior parte atendendo ao SOME, salienta duas perspectivas de formação que acontecem no SOME de modo concomitante: uma que fragmenta os saberes, quando não oferece as mínimas condições de trabalho aos profissionais da educação e a outra que integra os saberes, quando, mesmo diante das limitações, os professores conseguem "interagir" com a comunidade no sentido de compreender a realidade local para solucionar problemas.

Em relação à integração, este professor afirma que:

mas, tem professor que ele fica na comunidade, ele participa da comunidade, ele participa dos eventos da comunidade, ou seja, ele interage com a comunidade, quando ele interage com a comunidade aí a coisa é diferente, porque ele pode convocar os pais, se o aluno começa a dar problema ele vai saber quem são os pais daquele aluno justamente para tentar trabalhar esse problema junto com os pais.

Igualmente são saberes que se intercruzam de percepções antagônicas na formação das juventudes, mas que ocorrem concomitantemente nas relações socialmente construídas, nos momentos de socialização dos saberes dos Professores, dos alunos, da comunidade seja no fazer da farinha, seja no preparo do roçado, opondo-se à fragmentação dos saberes ao imprimir a descaracterização do ensino pela ausência de estrutura física, quando desnorteia o docente ao não pagamento de seus salários, quando impede a continuidade do ensino ao não 
ofertar condições estruturais aos docentes para permanecerem na comunidade, sendo, claramente, mecanismos de enfraquecimento do SOME.

Nota-se, que a integração incentivada pelos Professores do SOME, de outro modo, possibilitou uma transformação na vida desses sujeitos. No plano educacional, por exemplo, a transformação ocorreu, segundo a egressa Lúcia ${ }^{12}$, ancorada na organização da comunidade. De acordo com ela:

Houve sim. Antes do SOME, os eventos todos da comunidade eram organizados, promovidos, pela Igreja. Na época que chegou o SOME a maioria dos eventos que eram organizados eram feitos pelo SOME. Exposição de trabalho, feira cultural, aí sempre frisando, como era um número reduzido de aluno, todo mundo sabia, aí chegou o professor, ele chegava no barco de tarde e já reunia a comunidade para começarem as aulas no dia seguinte.

São saberes de concepção organizativa que, quando não se articulavam às necessidades da comunidade, produziam a fragmentação dos saberes repassados por meio das relações socialmente produzidas no cotidiano da Vila de Juaba, pois deixava de "fazer sentido". Lima (2011, p. 51) afirma ainda que “[...] neste sentido, na escola (exemplo privilegiado por esta perspectiva) ora se ligam objetivos, estruturas, recursos e atividades e se é fiel às normas alternativas; ora se respeita a conexão normativa, ora se rompe com ela e se promove a desconexão de fato".

Em relação à Vila de Juaba, assume-se que, nos processos formativos materializados a partir dos saberes dos jovens estudantes do SOME, coexistem práticas/processos que tendem a integrar e fragmentar os saberes socialmente construídos por aquela comunidade, "[...] não sendo exclusivamente uma coisa ou outra poderá ser simultaneamente as duas [...]" (LIMA 2011, p. 51). Lopes ${ }^{13}$, egresso do SOME, esclarece ainda, sobre esta perspectiva das práticas dos professores, o quão foi relevante este ensino em sua formação. Segundo ele:

Nas manifestações culturais em julho existe o evento aqui que também é organizado
pelo SOME, o festival que acontece no mês de julho, ele dá uma mexida na
economia né? Não somente a organização do evento que por fazer o evento lá, mas
as pessoas que se beneficiam, para quem vende seus produtos [...] Que foi, na
verdade, a partir daí que eu passei a enxergar aquilo que eu queria, que foi chegar a
me formar para ser professor, já foi a partir daí que eu passei a me identificar
realmente com a disciplina e foi aí que eu me imaginei, que ainda não conclui, mas
eu quero chegar que é atuar na sala de aula.

Não se desconhece, porém, que apenas a prática dos Professores em ajudar, junto com os alunos, a organizar o Festival Juabense, evidenciada na fala dos egressos, seja o bastante

\footnotetext{
${ }^{12}$ Nome fictício adotado para preservar a face pública da entrevistada.

${ }^{13}$ Nome fictício criado para preservar a face pública do entrevistado.
} 
para a constituição do sujeito em sua totalidade, bem como para a sua formação sob a forma de garantia de seus direitos pela afirmação de classe e por meio do sentimento de identidade com o movimento de organização em favor de um objetivo comum: o Festival Juabense.

Há que se compreender, porém, que a integração dos saberes dos egressos e da comunidade aos científicos, por meio dos processos formativos no SOME, revela-se como mecanismo que incorpora e fortalece as lutas pela constituição do ser social de que fala Lukács (1968), do sujeito em sua completude, e que as ações dos Professores, por meio dos processos formativos, colaboram para a formação desse sujeito consciente.

A constituição do ser social, no dizer de Lukács (1968, p. 3), em uma concepção marxiana, baseia-se em perceber sua ontologia: “[...] em primeiro lugar, o ser em seu conjunto é visto como um processo histórico; em segundo, as características não são tidas como enunciados sobre algo que é ou que se torna, mas sim como formas moventes e movidas da própria matéria [...]”, interessando, aqui, assumir que a consciência é reflexo da realidade, tornando possível intervir nela para modificá-la, tendo a consciência papel decisivo nesse processo e trazendo à luz a formação enquanto propulsora da construção dessa consciência, isso por meio de processos formativos que partam da realidade dos jovens.

No interior da relação entre os saberes científicos e os saberes dos discentes, aparece outro, que é construído, mediado por processos formativos, que permite a construção do saber, que tem na atitude ético-política do docente um mecanismo de enfrentamento contra as ações do capital e de fortalecimento político da comunidade a partir de processos de articulação dos saberes do cotidiano.

Atentemos para as palavras do Raimundo ${ }^{14}$ sobre práticas constitutivas do sujeito ético-político:

\begin{abstract}
Olha, eu posso falar por mim, eu sou inimigo da escola, eu faço tudo para o aluno não colar. Por isso que eu explico, reexplico, falo, comento, eu acho que a cola no meu ponto de vista é um ato ilícito e isso vai para sociedade. O que é mais fácil para ti? Passar de ano colando ou estudando? Colando. O que é mais fácil tu crescer na vida em sociedade ou trabalhar honestamente ou roubando? Roubando. Segundo essas visões que você vê no dia a dia que vem dessa coisa da cola. E pior que não fica só nos alunos, se é um aluno que tira nota 10 aqui que colou o outro que tirou 6 e não colou ele ainda vem dizer que é idiotice não colar. Ele ainda incentiva os outros a cometerem um ato ilícito.
\end{abstract}

Práticas desenvolvidas sob esta perspectiva possibilitam a solução de questões didáticas envolvendo posicionamento ético-político docente. Desse modo, o compromisso com as opções políticas e educacionais emancipadoras nas práticas formativas é mecanismo

\footnotetext{
${ }^{14}$ Nome fictício adotado para preservar a face pública do entrevistado.
} 
de construção do sujeito também ético-político, colaborando ainda para que o Ensino Médio faça sentido na vida do estudante, pois fortalece a integração dos saberes de Professores aos saberes de alunos e comunidade por meio das práticas que compreendem o cotidiano dos sujeitos envolvidos nesse processo de construção de saberes.

Tomamos a ideia de integração como um princípio pedagógico orientador de práticas formativas focadas na necessidade de desenvolver nas pessoas (crianças, jovens e adultos) a ampliação de sua capacidade de compreensão de sua realidade específica e da relação desta com a totalidade social. Essa forma de compreender o ensino integrado exige a crítica às perspectivas reducionistas de ensino, que se comprometem em desenvolver algumas atividades humanas em detrimento de outras e que, em geral, reservam aos estudantes de origem trabalhadora o desenvolvimento de capacidades cognitivas básicas e instrumentais em detrimento do desenvolvimento de sua força criativa e de sua autonomia intelectual e política (ARAUJO, 2013, p. 1).

A ampliação da percepção da atividade do homem em contraposição à sua alienação em uma concepção marxiana de práxis e tendo o homem como mediador desse processo, que práxis “[...] é, portanto, a revolução, ou crítica radical que, correspondendo às necessidades radicais, humanas, passa do plano teórico ao prático". No caso do SOME, ele oportunizou uma mudança na vida dos sujeitos, consubstanciando em uma práxis política porque foi por meio dos processos formativos integradores que ocorreu a transformação na vida dos sujeitos (VASQUEZ, 2011, p. 76).

A integração entre a prática social e o conhecimento organizado é fator determinante para o desenvolvimento de práticas de atuação transformadoras da realidade.

O ensino precisa estar calcado na experiência social concreta dos alunos, exigindo
também uma atuação fundamental do professor que vai transformar a massa de
conhecimentos existentes numa matéria preparada, ordenada e simplificada para ser
assimilada pelo aluno. Aí é que se encontra o cerne do trabalho pedagógico: no
confronto da prática social do aluno com o conhecimento organizado trazido pelo
professor, o que propicia o desenvolvimento de novas formas de atuação sobre a
realidade (MARLI; MEDIANO, 2013, p. 191).

O Ensino Médio, sob esta perspectiva, não seria apenas uma forma de integrar os saberes, mas uma proposição de formação que compreende a importância da formação inteira, com possibilidades de sistematização da cultura de um processo formativo que promova o desenvolvimento de suas capacidades em suas múltiplas dimensões, ou seja, "[...] de trabalhar, de viver coletivamente e agir autonomamente sobre a realidade, contribuindo para a construção de uma sociabilidade de fraternidade e de justiça social (ARAUJO, 2014, p. 68).

Em sua essência, a constituição dos saberes sociais, aqui defendida, surge da integração dos saberes organizativos dos egressos aos saberes historicamente acumulados pela 
humanidade, no caso do SOME, decorrentes de uma necessidade em modificar sua realidade, buscando saberes que possam consubstanciar processos formativos que ofertem formação com perspectivas de "nível mais elevado de estudo" e/ou inserção imediata no mercado de trabalho, já que o SOME, no recorte temporal, foi também profissionalizante, considerando, ainda, o contexto da produção dessa formação, desses saberes, isto porque:

[...] Toda "aplicação" de princípios técnicos-científicos é sempre, em parte, uma reinvenção local, e toda atividade entre estas normas é sempre, mais ou menos, uma "gramática do uso de si" situada entre estas normas antecedentes e a necessidade de dar-se a si mesmo normas, aí onde as primeiras são "inacabadas (SCHWARTZ, 2003, p. 12).

A organização da comunidade evidenciada nos processos formativos efetivados nas práticas dos docentes do SOME foi se constituindo elemento relevante para que os jovens da Vila de Juaba buscassem, por meio de sua organização política, a integração dos saberes dos Professores aos saberes das experiências por eles vivenciadas na comunidade, nas relações de trabalho, nas relações de lazer, ou seja, o processo de organização política mediado pelo SOME, como já exposto, foi possível por se tratar de organização por meio das relações socialmente construídas nas vivências desses sujeitos da comunidade da Vila de Juaba.

Sustenta-se, que a atitude ético-política docente presenciou desafios em materializar processos formativos integradores no SOME, mas que os sujeitos inseridos no processo de integração de saberes enquanto forma de fortalecimento da classe trabalhadora em prol de seus interesses constituíam em suas práticas, seja de aprendizagem, seja de ensino, atitudes humanas capazes de elucidar a transformação social, com o compromisso político com a formação dos trabalhadores, conscientes de que é na Escola que a face da sociedade é reproduzida e, dependendo do caso, materializada. Esse processo de construção de atitudes humanas somente foi possível pela presença dos docentes na Vila de Juaba.

Alerta-se que somente as práticas formativas de Professores, bem como de alunos discentes e da comunidade, não sejam o bastante para a formação do sujeito em sua completude. Também as condições objetivas de sua realização devem ser garantidas, compreendendo que a materialização de um ambiente favorável é elemento que pressupõe a integração, considerando a realidade social e os sujeitos participantes desse processo.

\section{CONSIDERAÇÕES FINAIS}

No contexto sócio histórico analisado, os egressos do SOME desenvolveram organização política por meio das relações sociais na Vila de Juaba, como possibilidade de 
construção contra as ações do capital e corroborando com seus interesses. Essa organização política dos egressos favoreceu o desenvolvimento de processos formativos no SOME que integraram os saberes do cotidiano aos saberes científicos e, aqui, esta integração é considerada como saberes sociais.

Contudo, nesses processos formativos, que integraram os saberes sociais, foram desenvolvidas práticas que resultaram em disputas materializadas em processos formativos outros, por exemplo, a negação do Estado em assegurar ensino de qualidade aos egressos, não oferecendo-lhes condições de estruturas físicas adequadas ao bom andamento das atividades escolares, mas esse Estado também ofertou, mesmo sob condições adversas, Ensino Médio para uma região antes não atendida por esse nível de ensino, importante para o desenvolvimento de organização política e prosseguimento do ensino defendido pelos egressos e comunidade de Juaba.

O fortalecimento político dos egressos se deu ao perceberem que o SOME, uma política de Estado, possibilitaria progresso para a região em ofertar Ensino Médio onde antes não existia, convergindo para o entendimento de que a integração dos saberes sociais era importante para a constituição dos egressos como seres sociais por meio de processos formativos potencializadores que valorizaram a organização política, configurando ainda entre os egressos a sua legitimação de classe em intervir a favor de seus interesses.

Considera-se que a práxis política desenvolvida a partir da organização dos egressos em meio às suas relações sociais teve como produto uma relação indissolúvel entre os saberes sociais, mas que tiveram em sua constituição processos formativos fragmentários e processos formativos integradores, possibilitando a organização política que colaborou com a mudança na realidade dos egressos.

Da empiria infere-se que os egressos produziram saberes sociais impulsionados por sua organização política por meio de processos formativos, mas esses processos aconteceram de forma dialética, pois no interior dessa formação ofertada no SOME surgiram elementos da oferta do ensino para cumprimento burocrático, o que favorece a fragmentação de saberes, além de elementos como a atitude ético-política docente que fomentou a construção de uma formação como forma de resistência às ações do capital.

Outra reflexão importante a ser considerada foi aprofundar a leitura da oferta do SOME como objeto das lutas de classes, preconizando a gênese da fragmentação dos saberes com a Divisão Técnica do Trabalho que posteriormente, na década de 1990, período de implantação do SOME em Juaba, esteve ancorada na perspectiva da globalização neoliberal. 
As análises permitiram, também, entender que, além da formação ofertada no SOME por meio de seus processos formativos desenvolvidos em integração com os sujeitos inseridos nesses processos, a integração dos saberes é importante como elemento nuclear para a compreensão da construção do ser social jovem, objetivando a superação dos problemas sociais, educacionais, econômicos, ou seja, por meio da organização política, o egresso passa a ter condição de transformar a sua realidade.

Esta investigação, assim analisada, fundamentada pelo estudo de caso, examinando uma determinada realidade social e educativa, permite também a compreensão de elementos universais, porque a produção de saberes tem um viés que passa pela produção da cultura que é acumulada historicamente pela humanidade.

\section{REFERÊNCIAS}

BRASIL. Ministério da Educação. Decreto no 2.208, de 17 de abril de 1997.

BRASIL. Ministério da Educação. Decreto no 5.154, de 23 de julho de 2004. Disponível em<http://etsus.ms.gov.br/wp-content/uploads/sites/64/2015/04/DECRETO_5154.pdf>.

Acesso em: 17 mar. 2016.

BRASIL. Congresso Nacional. LEI No 9.394 de 20 de dezembro de 1996. Disponível em $<$ http://portal.mec.gov.br/seesp/arquivos/pdf/lei9394_ldbn1.pdf $>$. Acesso em: 25 mar. 2016.

FRIGOTTO, G.; CiAVATTA, M.; RAMOS, M. (Orgs.). Ensino Médio Integrado: concepções e contradições. São Paulo: Cortez, 2005.

GRAMSCI, A. Os intelectuais e a organização da cultura. 4. ed. Rio de Janeiro: Civilização Brasileira, 1982.

LUKÁCS, G. As bases ontológicas do trabalho e da atividade do homem. In: CONGRESSO FILÓSÓFICO MUNDIAL. Viena, 1969. Anais... Viena, 1969.

KOSIK, K. Dialética do concreto. 2 ed. Rio de Janeiro: Paz e Terra, 1976.

MANACORDA, M. A. O princípio educativo em Gramsci: americanismo e conformismo. Campinas: Editora alínea, 2008. (Col. Educação em debate).

NOSELLA, P. Ensino médio à luz de Gramsci. Campinas: Editora Alínea, 2016.

OLIVEIRA, D. Por uma educação profissional democrática e emancipatória. In: OLIVEIRA, R. Jovens e Ensino Médio profissional: Políticas públicas em debate. Campinas: Papirus, 2012. (Col. Papirus Educação). 
PARÁ. Assembleia Legislativa do Estado do Pará. Lei n. 7.806, de 29 de abril de 2014. Disponível em < www.pge.pa.gov.br/sites/default/files/lo7806.pdf> Acesso em: 25 mar. 2016.

PISTRAK, M.M. Fundamentos da escola do trabalho. São Paulo: Expressão popular, 2011.

RUMMENT, S.M. Educação de jovens e adultos trabalhadores e a produção social da existência. In: TIRIBA, L.; CIAVATTA, M. (Orgs). Trabalho e educação de jovens e adultos. Brasília: Liber Livro, 2011.

SOLEDADE, E. V.; SILVA, G. P. O Ensino Médio no Estado do Pará: a experiência do Ensino Modular. In: OLIVEIRA, J.P.G.; RODRIGUES, D.S.; PRAZERES, M. S. C.; MENDES, O. C. (Orgs.). Educação, identidade e conhecimento na Amazônia Tocantina: diálogos científicos. Cametá: Campus Universitário do Tocantins, 2013.

SNYDERS, G. Escola, classes e lutas de classes. São Paulo: Martins e Fontes, 1976. (Col. Psicologia e Pedagogia).

TARDIF, M. Saberes profissionais dos professores e conhecimentos universitários. Revista Brasileira de Educação, n. 13, 2000.

VÁZQUEZ, A. S. Filosofia da Práxis. 2. ed. Buenos Aires: Consejo Latinoamericano de Ciencias Sociales; São Paulo: Expressão Popular, 2011.

Recebido em 27.03.2019

Aprovado em 09.04.2019 